\title{
Tenascin-R Restricts Posttraumatic Remodeling of Motoneuron Innervation and Functional Recovery after Spinal Cord Injury in Adult Mice
}

\author{
Ivayla Apostolova, ${ }^{*}$ Andrey Irintchev, ${ }^{*}$ and Melitta Schachner \\ Zentrum für Molekulare Neurobiologie, Universität Hamburg, D-20246 Hamburg, Germany
}

\begin{abstract}
Tenascin-R (TNR) is an extracellular glycoprotein in the CNS implicated in neural development and plasticity. Its repellent properties for growing axons in a choice situation with a conducive substrate in vitro have indicated that TNR may impede regeneration in the adult mammalian CNS. Here we tested whether constitutive lack of TNR has beneficial impacts on recovery from spinal cord injury in adult mice. Using the Basso, Beattie, Bresnahan (BBB) locomotor rating scale, we found that open-field locomotion in TNR-deficient $\left(T N R^{-1-}\right)$ mice recovered better that in wild-type $\left(T N R^{+/+}\right)$littermates after compression of the thoracic spinal cord. We also designed, validated, and applied a motion analysis approach allowing numerical assessment of motor functions. We found, in agreement with the BBB score, that functions requiring low levels of supraspinal control such as plantar stepping improved more in $T N R^{-1-}$ mice. This was not the case for motor tasks demanding precision such as ladder climbing. Morphological analyses revealed no evidence that improved recovery of some functions in the mutant mice were attributable to enhanced tissue sparing or axonal regrowth. Estimates of perisomatic puncta revealed reduced innervation by cholinergic and GABAergic terminals around motoneurons in intact $T N R^{-/-}$compared with $T N R^{+/+}$ mice. Relative to nonlesioned animals, spinal cord repair was associated with increase in GABAergic and decrease of glutamatergic puncta in $T N R^{-/-}$but not in $T N R^{+/+}$mice. Our results suggest that TNR restricts functional recovery by limiting posttraumatic remodeling of synapses around motoneuronal cell bodies where TNR is normally expressed in perineuronal nets.
\end{abstract}

Key words: functional recovery; motion analysis; mouse; tenascin-R; spinal cord injury; synaptic plasticity

\section{Introduction}

Tenascin-R (TNR) is an extracellular matrix molecule expressed by oligodendrocytes and subpopulations of neurons in the adult CNS of vertebrates (Schachner, 1997; Dityatev and Schachner, 2003). The glycoprotein is accumulated around nodes of Ranvier and in perineuronal nets surrounding motoneurons and subpopulations of interneurons. TNR regulates inhibitory perisomatic inhibition via interactions of its HNK-1 (human natural killer cell) carbohydrate epitope with $\mathrm{GABA}_{\mathrm{B}}$ receptors and thus influences synaptic transmission and plasticity in the hippocampus (Saghatelyan et al., 2000, 2001; Bukalo et al., 2001; Dityatev and Schachner, 2003; Brenneke et al., 2004). In myelinated CNS axons, TNR is a functional modulator of the $\beta$-subunit of voltage-gated sodium channels (Srinivasan et al., 1998; Xiao et al., 1999). In vitro experiments have shown that neurites of retinal and dorsal root ganglion cells and cerebellar neurons are repelled by a substrate border of TNR (Pesheva et al., 1993; Taylor et al.,

Received April 9, 2006; revised May 23, 2006; accepted June 20, 2006.

This work was supported by the Erika und Conrad Schnyder-Stiftung, the Daniel Heumann Fund for Spinal Cord Research, and the Deutsche Forschungsgemeinschaft (SCHA 185/29-3, 4). We are grateful to Dr. Alexander Dityatev for critical comments on this manuscript and to Emanuela Szpotowicz for technical assistance.

*I.A. and A.I. contributed equally to this work.

Correspondence should be addressed to Melitta Schachner or Andrey Irintchev, Zentrum für Molekulare Neurobiologie, Universität Hamburg, Martinistrasse 52, D-20246 Hamburg, Germany. E-mail: melitta.schachner@zmnh.uni-hamburg.de or andrey.rintchev@zmnh.uni-hamburg.de.

D0I:10.1523/JNEUROSCI.1526-06.2006

Copyright $\odot 2006$ Society for Neuroscience $\quad$ 0270-6474/06/267849-11\$15.00/0
1993; Becker et al., 2000). TNR also has inhibitory functions in the outgrowth and guidance of optic axons in vivo (Becker et al., 1999, 2003, 2004). Also, it has been observed that TNR influences a variety of microglial functions such as cell adhesion and migration and secretion of cytokines and growth factors (Angelov et al., 1998; Liao et al., 2005). All of these findings indicate that TNR is an important modulator of plasticity and repair processes in the CNS.

After spinal cord injury (SCI), TNR expression is upregulated in the lesion area (Deckner et al., 2000). It has been suggested that this glycoprotein is among the oligodendrocyte-derived molecules inhibiting axonal regrowth after SCI (Pesheva and Probstmeier, 2000; Sandvig et al., 2004). Here we tested the hypothesis that TNR is a molecule restraining recovery from SCI by analysis of TNR null mutant mice and wild-type littermates in a compression SCI paradigm. The TNR-deficient mice are vital and fertile, have a normal lifespan, and have no gross anatomical or histological abnormalities (Weber et al., 1999). They show motor deficits under demanding conditions (rotarod, pole, and wirehanging tests), but otherwise their gate and motor behavior appear normal (Freitag et al., 2003). We used classical approaches to evaluate the outcome of SCI including locomotor scale rating (Basso et al., 1995), as well as axonal tracing and immunohistochemical techniques. In addition, we applied analyses of synaptic coverage and a novel approach for evaluation of motor functions based on principles recently applied for analysis of motor function after femoral nerve injury in mice (single-frame motion 
analysis) (Irintchev et al., 2005b). The data collected by different methods provide evidence that TNR is a molecule restricting recovery from SCI in mice.

\section{Materials and Methods \\ Animals}

Female C57BL/6J as well as TNR-deficient $\left(T N R^{-/-}\right)$mice and control wild-type $\left(T N R^{+/+}\right)$littermates (Weber et al., 1999) were obtained from the animal facility of the Universitätsklinikum Hamburg-Eppendorf (Hamburg, Germany) at the age of 3 months. Genotyping of the mice from the TNR stock was performed using PCR assays. The animals were kept under standard laboratory conditions. All experiments were conducted in accordance with the German and European Community laws on protection of experimental animals, and the procedures used were approved by the responsible committee of The State of Hamburg. Animal treatments, collection of data, and data analyses were performed blindly. Numbers of animals studied in different experimental groups and at different time periods after surgery are given in the text and figures.

\section{Surgical procedures}

For surgery, the mice were anesthetized by intraperitoneal injections of ketamine and xylazine [100 mg of Ketanest (Parke-Davis/Pfizer, Karlsruhe, Germany) and $5 \mathrm{mg}$ of Rompun (Bayer, Leverkusen, Germany) per kg body weight]. Laminectomy was performed at the T7-T9 level with mouse laminectomy forceps (Fine Science Tools, Heidelberg, Germany). A mouse spinal cord compression device was used for compression injury (Curtis et al., 1993; Steward et al., 2003). The device consisted of a pair of watchmaker forceps mounted in a metal block attached to a stereotaxic frame. Compression force (degree of closure of the forceps) and duration were controlled by an electromagnetic device. In most cases, the spinal cord was maximally compressed (100\%, according to the operational definition of Curtis et al., 1993) for $1 \mathrm{~s}$ by a timecontrolled current flow through the electromagnetic device. To produce a milder injury, in some animals, the compression force was reduced to $50 \%$. The skin was then surgically closed using 6-0 nylon stitches (Ethicon, Norderstedt, Germany). After the operation, mice were kept in a warm room $\left(35^{\circ} \mathrm{C}\right)$ for several hours to prevent hypothermia and thereafter singly housed in a temperature-controlled $\left(22^{\circ} \mathrm{C}\right)$ room with water and standard food provided ad libitum. During the postoperative time period, the bladders of the animals were manually voided twice daily.

\section{Analysis of motor function}

Locomotor rating. The recovery of ground locomotion was evaluated using the Basso, Beattie, Bresnahan (BBB) rat rating scale (Basso et al., 1995) as modified for the mouse by Joshi and Fehlings (2002). More recent modifications of the rating scale for mice (Engesser-Cesar et al., 2005; Li et al., 2006) were not used because they were published when our investigations were in an advanced stage. Scoring was done by one and the same investigator. Motor performance of each animal was evaluated during free movement in an open-field arena placed $90 \mathrm{~cm}$ over ground to aid close observations of the mice (Joshi and Fehlings, 2002). Rating of each animal was later checked by analysis of video recordings of beam walking (see below) observed at slow playback speed. Assessment was performed at 1, 3, and 6 weeks after injury. Scores for the left and right extremities were averaged.

Single-frame motion analysis. In preliminary experiments, we adapted our novel approach for evaluation of motor function, the single-frame motion analysis (Irintchev et al., 2005b) developed for the femoral nerve injury paradigm, for assessment of recovery after spinal cord lesion. The following description refers to the test conditions and evaluation parameters defined as optimal in pilot studies and used in the analyses reported in Results. Mice were trained to perform a classical beam-walking test. In this test, the animal walks unforced from one end of a horizontal beam (900 mm length, $40 \mathrm{~mm}$ width) toward its home cage located at the other end of the beam. A left- and right-side view of each animal during two consecutive walking trials were captured before the operation with a Panasonic (Hamburg, Germany) NV-DS12 camera at 25 frames per second and recorded on videotape (video recorder SVL-SE 830; Sony, Co- logne, Germany). The recordings were repeated 1, 3, and 6 weeks after spinal cord lesion. The video sequences were digitized and examined with VirtualDub software, a video capture/processing utility written by Avery Lee (free software available at http://www.virtualdub.org). Selected frames in which the animals were seen in defined phases of locomotion (see below) were used for measurements performed with University of Texas Health Science Center at San Antonia Image Tool 2.0 software (University of Texas, San Antonio, TX, free software available at http://ddsdx.uthscsa.edu/dig/). Two parameters, which we designated foot-stepping angle and rump-height index, were measured. The footstepping angle is defined by a line parallel to the dorsal surface of the hindpaw and the horizontal line (Fig. $1 A-C$ ). The angle is measured with respect to the posterior aspect at the beginning of the stance phase. In intact mice, this phase is well defined and the angle is smaller than $20^{\circ}$ (Fig. 2B). The average of three to five measurements per animal, extremity, and trial was found to be representative for the individual animals. After spinal cord injury and severe loss of locomotor abilities, the mice drag behind their hindlimbs with dorsal paw surfaces facing the beam surface (Fig. $1 A$ ). The angle is increased to $>150^{\circ}$ (Figs. $1 A, 2 B$ ). In severely disabled mice, video frames for analysis were selected from three to five different "step cycles" delineated by the forelimbs. The video frames in which the angle appeared to have its lowest values for individual "cycles," typically after a visible attempt to flex the extremity, were selected for measurements. In less severely disabled mice that performed stepping of variable quality (dorsal or plantar), the angle was measured on dorsal or ventral placement of the paw on the ground after a swing phase or after a forward sliding of the paw over the beam surface (Fig. $1 C)$. Step cycles were defined, depending on the capabilities of the individual animals, according to the criteria outlined above for intact or severely disabled mice. The values for the left and right leg of individual mice were averaged. The foot-stepping angle was defined as and proved to be (see Results) a numerical parameter allowing objective assessment of the plantar stepping ability, one of the major behavioral aspects assessed by the BBB score.

The second parameter, the rump-height index, was estimated from the recordings used for measurements of the foot-stepping angle. The parameter is defined as height of the rump, i.e., the vertical distance from the dorsal aspect of the animal's tail base to the beam, normalized to the thickness of the beam measured along the same vertical line (Fig. $1 A-C$ ). For each animal and trial, at least three frames in which the rump height was maximal during different step cycles, defined according to the stepping ability of the animal as described above, were used for measurements. The rump-height index is a numerical estimate of the ability to support body weight. This ability requires coordination in different joints of both hind extremities and is influenced by various factors such as stepping art (plantar vs dorsal), muscle strength, and spasticity (supplemental Fig. 1, available at www.jneurosci.org as supplemental material).

A third parameter, the limb extension-flexion ratio, was evaluated from video recordings of voluntary movements of the mice performed during the "pencil" test described for the femoral nerve injury paradigm (Irintchev et al., 2005b). An intact mouse, when held by its tail and allowed to grasp a pencil with its forepaws, tries to catch the object with its hindpaws and performs cycling flexion-extension movements with the hindlimbs (Fig. 1D,E) (Irintchev et al., 2005b, their Fig. 1i,j and supplemental videos 5,6 ). For the spinal cord injury paradigm, leftand right-side view videos were recorded for each animal. The extension and flexion length of the extremity (distance from the most distal midpoint of the paw to a fixed, well discernible point on the animal's body, e.g., the tail base) were measured for at least three extensionflexion cycles per animal and time point. Mean values for the two extremities from one animal were averaged. The extension-flexion ratio is a numerical estimate of the animal's ability to initiate and perform voluntary, nonweight-bearing movements. Such movements require connectivity of the spinal cord to supraspinal motor control centers but, in the form evaluated here, no coordination or precision.

Ladder-climbing test. Grid walking and horizontal ladder crossing have been used as tests for evaluation of "skilled walking," which is dependent on descending motor control and ascending flow of proprioceptive and 

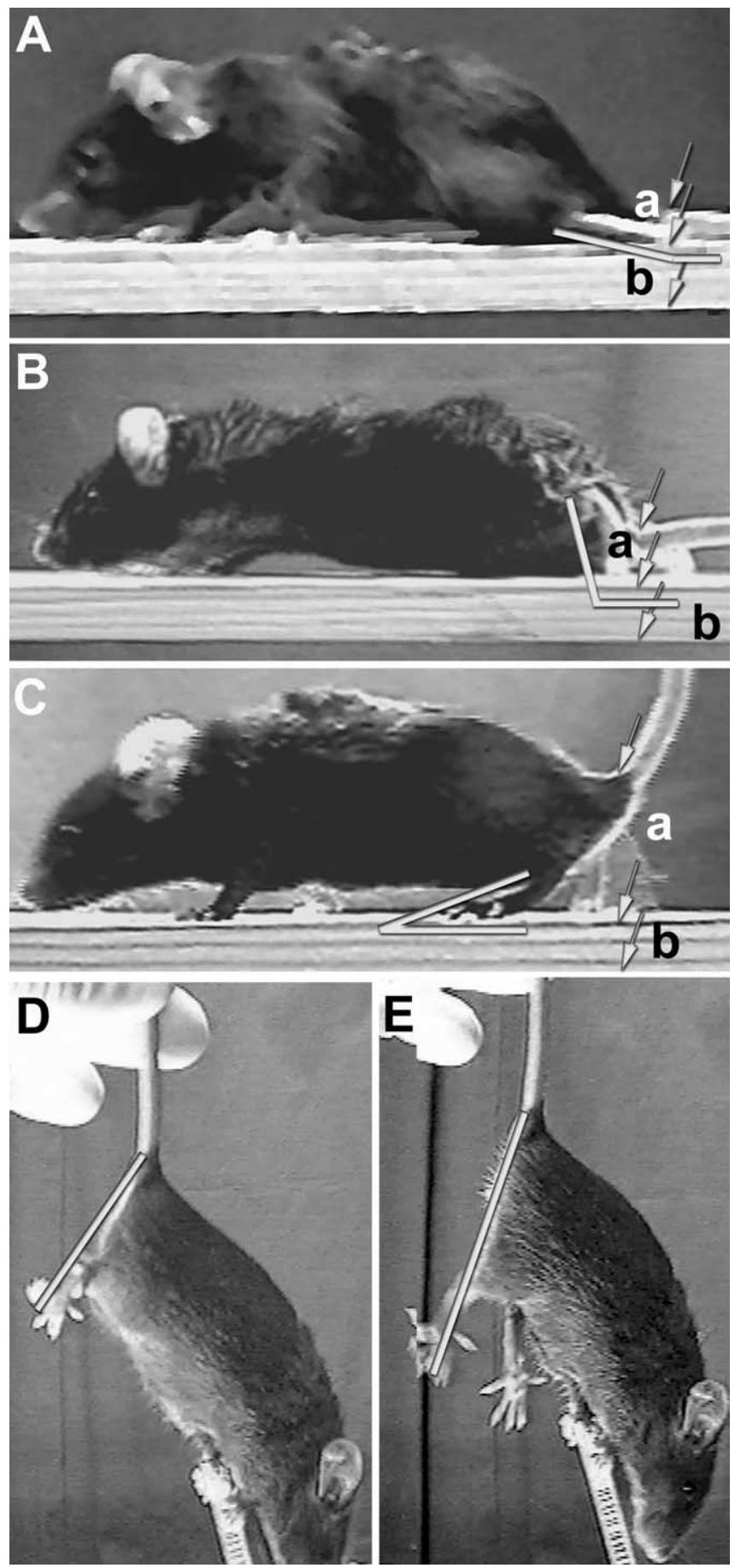

Figure 1. Single-frame motion analysis. Single frames of video sequences recorded during beam walking $(\boldsymbol{A}-\boldsymbol{C})$ and voluntary movements without body weight support (pencil test; $\boldsymbol{D}, \boldsymbol{E}$ ) of mice subjected to severe $(\boldsymbol{A}, \boldsymbol{B})$ or moderate $(\boldsymbol{C}-\boldsymbol{E})$ spinal cord compression. The animals were video recorded at $1(\boldsymbol{A}), 3(\boldsymbol{B})$, and $6(\boldsymbol{C}-\boldsymbol{E})$ weeks after injury. The foot-stepping angle, measured with respect to caudal, is drawn in $\boldsymbol{A}-\boldsymbol{C}$. The lengths of the distances $a$ and $b$ between the arrows were used to calculate the rump-height index. $\boldsymbol{D}$ and $\boldsymbol{E}$ show a phase of maximum hindlimb flexion (D) immediately followed by a maximum extension (E). The lengths of the lines drawn in the pictures were used to determine the extension-flexion ratio.

tactile information (Soblosky et al., 1997; Metz et al., 2000). In these tests, the animals walk across a grid or a horizontal ladder with rungs of equal or uneven spacing. The number of mistakes, misses, or slips per crossing or per unit time are used for evaluation. However, in cases of severe paraplegia, these tests are useless because the animals drag behind their legs and slips are rarely seen. We modified the ladder-crossing test to a ladder-climbing one. Preliminary experiments showed that, even without training, mice climb up rapidly an inclined ladder with rare explorative stops and never turn back to descend the ladder. This apparently instinctive behavior is preserved even in severely disabled animals that climb, although slowly, up to the top of the ladder using their forelimbs. The inclined position of the ladder provides body weight support for disabled mice and thus aids climbing. Also, the inclination of the ladder makes sliding of the paralyzed legs along the rungs impossible, and the extremities constantly protrude through the inter-rung spaces except in cases of correct and sustained placing of the paw. As a ladder, we used a 4-mm-thick frame made of a Resopal plate $(96 \mathrm{~cm}$ long, $12 \mathrm{~cm}$ wide, with central incision of $88 \times 6 \mathrm{~cm}$; Resopal, Gross-Umstadt, Germany) to which 43 round wooden rungs $(100 \times 2 \mathrm{~mm})$ were glued at equal intervals $(2 \mathrm{~cm})$. The ladder was fixed in an inclined position $\left(55^{\circ}\right)$ using a Plexiglas platform. The mice were placed at the bottom rungs of the ladder, and climbing was video recorded from a position "below" the ladder, i.e., viewing the ventral aspect of the animals. The video recordings were observed at slow-speed playback, and the number of correct steps (correct placing of the hindpaw and sustained position until the next forward move) over 36 rungs were counted. Intact animals typically stepped on every second rung, i.e., using $<20$ correct steps (averaged for the two extremities) to cross the 36-rung distance. Injured mice made between 0 and 10 correct steps depending on the injury severity and degree of recovery. These initial observations indicated that the ladderclimbing test could provide an opportunity for quantitative evaluation of complex motor behavior for the whole span of functional capabilities, from the non-injured state to complete paralysis.

Recovery indices. We previously introduced relative estimates of functional recovery after femoral nerve injury, the recovery indices (Irintchev et al., 2005b). The recovery index (RI) is an individual animal estimate for any given parameter described above and is calculated (percentage) as follows: $\mathrm{RI}=\left[\left(X_{7+n}-X_{7}\right) /\left(X_{0}-X_{7}\right)\right] \times 100$, where $X_{0}, X_{7}$, and $X_{7+n}$ are values before operation, $7 \mathrm{~d}$ after injury, and a time point $n$ days after the spinal cord injury, respectively. In simpler terms, this measure estimates gain of function $\left(X_{7+n}-X_{7}\right)$ as a fraction of the functional loss $\left(X_{0}-X_{7}\right)$ induced by the operation. It may attain 0 or negative values if no improvement or additional impairment occurs during the observation time period. The index cannot be calculated only if the operation causes no change in the value $\left(X_{0}-X_{7}=0\right)$. The recovery index is a meaningful and comprehensive parameter allowing better comparisons within one investigation and between results of different laboratories. Calculation of recovery indices is absolutely necessary if a parameter is prone to variability as a result of individual animal variability in body constitution and behavioral traits. An example is the rump-height index defined above. The index values are influenced not only by functional impairment but also by the animal's body size and the beam thickness. Overall recovery indices were calculated, on an individual animal basis, as means of recovery indices for individual parameters. The overall index is an estimate of the general condition of the treated animals based on individual objective measures. It is taken as a "clinical score" for individual mice similar to the BBB score, which is based on assessment of different aspects of locomotion. Recovery indices are to be interpreted in conjunction with analyses of all individual parameters measured to unequivocally identify the bases for the overall functional outcome.

\section{Retrograde labeling of neurons}

Six weeks after spinal cord compression, mice were anesthetized with ketamine and xylazine, and a complete transection of the spinal cord was performed one segment distally to the compression site. A Gelfoam pledget, trimmed to fit the cross-sectional area of the transected spinal cord $(\sim 2 \times 3 \mathrm{~mm})$ and soaked with $4 \%$ solution of the fluorescence retrograde tracer Fluoro-Gold (Fluorochrome, Denver, CO) in PBS, pH 7.3, was introduced into the transection site and placed at the rostral cut end of the spinal cord. After surgical closure of the wound, the mice were allowed to recover for a period of 2 weeks, a time period sufficient for retrograde transport and accumulation of the tracer in neuronal cel bodies, even in remote projection sites such as the cerebral cortex. The mice were then anesthetized with sodium pentobarbital $(5 \mu \mathrm{l} / \mathrm{g}$ body weight, i.p.; Narcoren; Merial, Hallbermoos, Germany) and transcardi- 
ally perfused with physiologic saline for $1 \mathrm{~min}$, followed by $4 \%$ formaldehyde in $0.1 \mathrm{~m}$ sodium cacodylate buffer, $\mathrm{pH} 7.3$, for $15 \mathrm{~min}$. The cervical spinal cords and the brains were removed, postfixed overnight in the same fixative at $4^{\circ} \mathrm{C}$, and cryoprotected by immersion in $15 \%$ sucrose solution in $0.1 \mathrm{~m}$ cacodylate buffer, $\mathrm{pH}$ 7.3 , for $2 \mathrm{~d}$ at $4^{\circ} \mathrm{C}$. The tissue was frozen for 2 $\min$ in 2-methyl-butane (isopentane) precooled to $-30^{\circ} \mathrm{C}$ in the cryostat. Serial coronal sections of $25 \mu \mathrm{m}$ thickness were obtained from the whole brain and the cervical spinal cord on a cryostat (CM3050; Leica, Nussloch, Germany). Sections were collected on SuperFrostPlus glass slides (Roth, Karlsruhe, Germany) so that four sections $250 \mu \mathrm{m}$ apart were present on each slide. One series of such spaced serial sections from the whole brain or cervical spinal cord were coverslipped using anti-fading medium [Fluoromount G; Southern Biotechnology Associates (Birmingham, AL) via Biozol, Eching, Germany] and observed on an epifluorescence microscope (Axioskop; Zeiss, Oberkochen, Germany) equipped with a motorized stage and Neurolucida softwarecontrolled computer system (MicroBrightField, Magdeburg, Germany). Retrogradely labeled cell profiles were counted bilaterally in areas with major projections to the spinal cord: cervical spinal cord, reticular formation, raphe nuclei, red nucleus, and the motor cortex.

\section{Histology and immunohistochemistry}

Six weeks after spinal cord injury, mice were transcardially perfused as described above, and parasagittal $25-\mu \mathrm{m}$-thick sections were obtained on a cryostat. For immunohistochemistry, the following commercially available antibodies were used at optimal dilutions: goat anticholine acetyltransferase antibody (ChAT) (1:100; Chemicon, Hofheim, Germany), guinea pig anti-serotonin transporter (5-HT-T) (1:1000; Chemicon), rabbit anti-tyrosine hydroxylase (TH) (1:800; Chemicon), mouse anti-tenascin-R (clone 619, 1:10) (Morganti et al., 1990), mouse anti-vesicular GABA transporter (VGAT) (1:1000; Synaptic Systems, Göttingen, Germany), and mouse anti-vesicular glutamate transporter 1 (VGLUT1) (1:500; Synaptic Systems). Biotin-conjugated lectin [Wisteria floribunda agglutinin (WFA); Sigma, Taufkirchen, Germany] was used at dilution of 1:500 to visualize perineuronal nets.

The staining protocol has been described previously (Irintchev et al., 2005a). Water-bath antigen demasking was performed in $0.01 \mathrm{M}$ sodium citrate solution, $\mathrm{pH} 9.0$, for $30 \mathrm{~min}$ at $80^{\circ} \mathrm{C}$ (Jiao et al., 1999) for all antigens except for TNR. Nonspecific binding was blocked using $5 \% \mathrm{v} / \mathrm{v}$ normal serum from the species in which the secondary antibody was produced, dissolved in PBS, and supplemented with $0.2 \% \mathrm{v} / \mathrm{v}$ Triton $\mathrm{X}-100$ and $0.02 \% \mathrm{w} / \mathrm{v}$ sodium azide for $1 \mathrm{~h}$ at room temperature (RT). Incubation with the primary antibody, diluted in PBS containing $0.5 \%$ $\mathrm{w} / \mathrm{v} \lambda$-carrageenan (Sigma) and $0.02 \% \mathrm{w} / \mathrm{v}$ sodium azide, was performed for $3 \mathrm{~d}$ at $4^{\circ} \mathrm{C}$. After washing in PBS (three times for $15 \mathrm{~min}$ at RT), the appropriate secondary antibody diluted 1:200 in PBS-carrageenan solution was applied for $2 \mathrm{~h}$ at RT. The following cyanine 3 (Cy3)-conjugated secondary antibodies were used: goat anti-rabbit, goat anti-mouse, donkey anti-goat, and donkey anti-guinea pig [Jackson ImmunoResearch (West Grove, PA) via Dianova, Hamburg, Germany]. After a subsequent wash in PBS, cell nuclei were stained for $10 \mathrm{~min}$ at RT with bis-benzimide solution (Hoechst 33258 dye, $5 \mu \mathrm{g} / \mathrm{ml}$ in PBS; Sigma). Finally, the sections were washed again, mounted in anti-fading medium (Fluoromount G; Southern Biotechnology Associates via Biozol), and stored in the dark at $4^{\circ} \mathrm{C}$. WFA staining was performed according to the same protocol using Cy3-streptavidin (1:200 in PBS; Jackson ImmunoResearch).

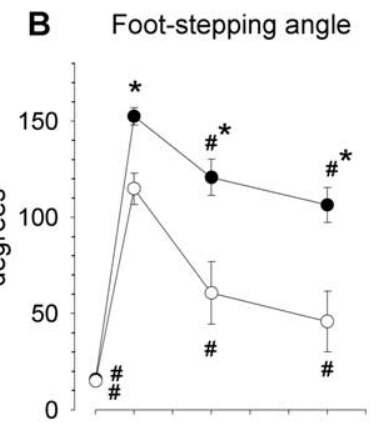

\section{Rump-height index}

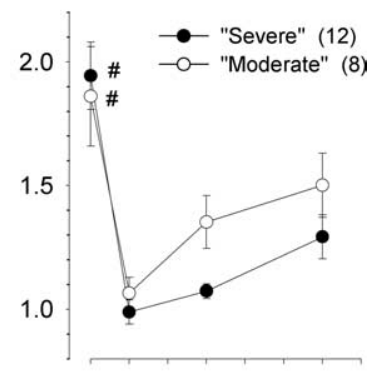

E

Correct steps
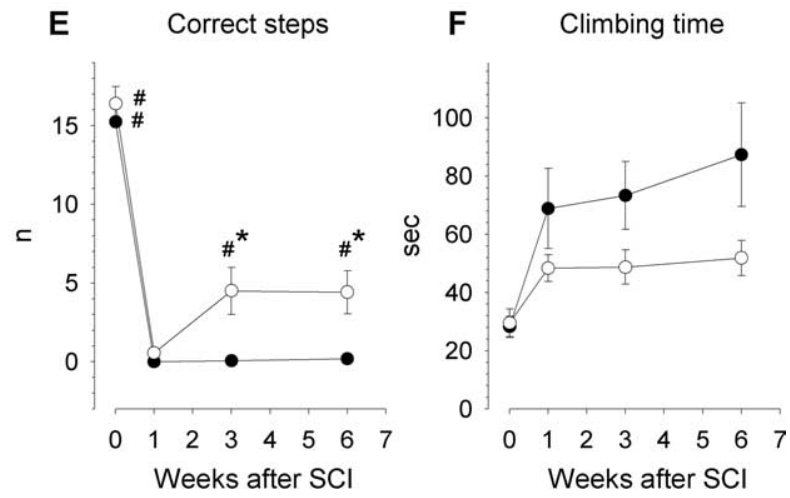

Figure 2. Time course and degree of functional recovery after moderate and severe spinal cord compression in $(57 \mathrm{BL} / 6 \mathrm{~J}$ mice. weeks after $\mathrm{SCl}$. Numbers of mice studied per group are given in $\mathbf{C}$. Symbols indicate significant differences between group mean values at a given time period $\left.{ }^{*}\right)$ or from the within-group value at 1 week afterinjury $\left({ }^{\#}\right)(p<0.05$, one-way ANOVA for repeated measurements with Tukey's post hoc test).

Motoneuron soma size and quantification of perisomatic puncta Estimations of soma areas and perisomatic puncta were performed as described previously (Irintchev et al., 2005a). Longitudinal spinal cord sections stained for ChAT, VGAT, or VGLUT1 were examined under a fluorescence microscope to select sections that contained motoneuron cell bodies over a distance of at least $500 \mu \mathrm{m}$ distal from the lesion scar. Stacks of images of $1 \mu \mathrm{m}$ thickness were obtained on an LSM 510 confocal microscope (Zeiss) using a $40 \times$ oil immersion objective and digital resolution of $1024 \times 1024$ pixels. Four adjacent stacks (frame size, $115 \times$ $115 \mu \mathrm{m}$ ) were obtained consecutively in a rostrocaudal direction so that motoneurons located both close and remote to the lesion scar were sampled. One image per cell at the level of the largest cell body cross-sectional area was used to measure soma area, perimeter, and number of perisomatic puncta (see Fig. $8 \mathrm{~A}-\mathrm{C}$ ). Motoneurons were identified by the immunolabeling in sections stained for ChAT (see Fig. $8 A$ ) and by the size of the cell bodies [unstained profiles surrounded by immunoreactive puncta (see Fig. $8 B, C$ )] and bis-benzimide counterstained nuclei (data not shown). Areas and perimeters were measured using the Image Tool 2.0 software program (University of Texas, San Antonio, TX, free software available at http://ddsdx.uthscsa.edu/dig/). Linear density was calculated as number of perisomatic puncta per unit length.

\section{Estimation of lesion scar volume}

C57BL/6J mice were subjected to spinal cord injury using compression forces of 50,75 , or $100 \%$ of maximum to produce variable degrees of lesion. Analysis of motor performance was made before and 1 and 6 weeks after operation. Afterward, the mice were perfused as described above, and the spinal cords were cut on the cryostat ( $25 \mu \mathrm{m}$ parasagittal sections). Spaced serial sections $250 \mu \mathrm{m}$ apart were stained with cresyl violet/Luxol fast blue and used for estimations of the scar volume using the Cavalieri principle. Areas of the scar required for volume estimation were measured directly under the microscope using the Neurolucida software (see above). 

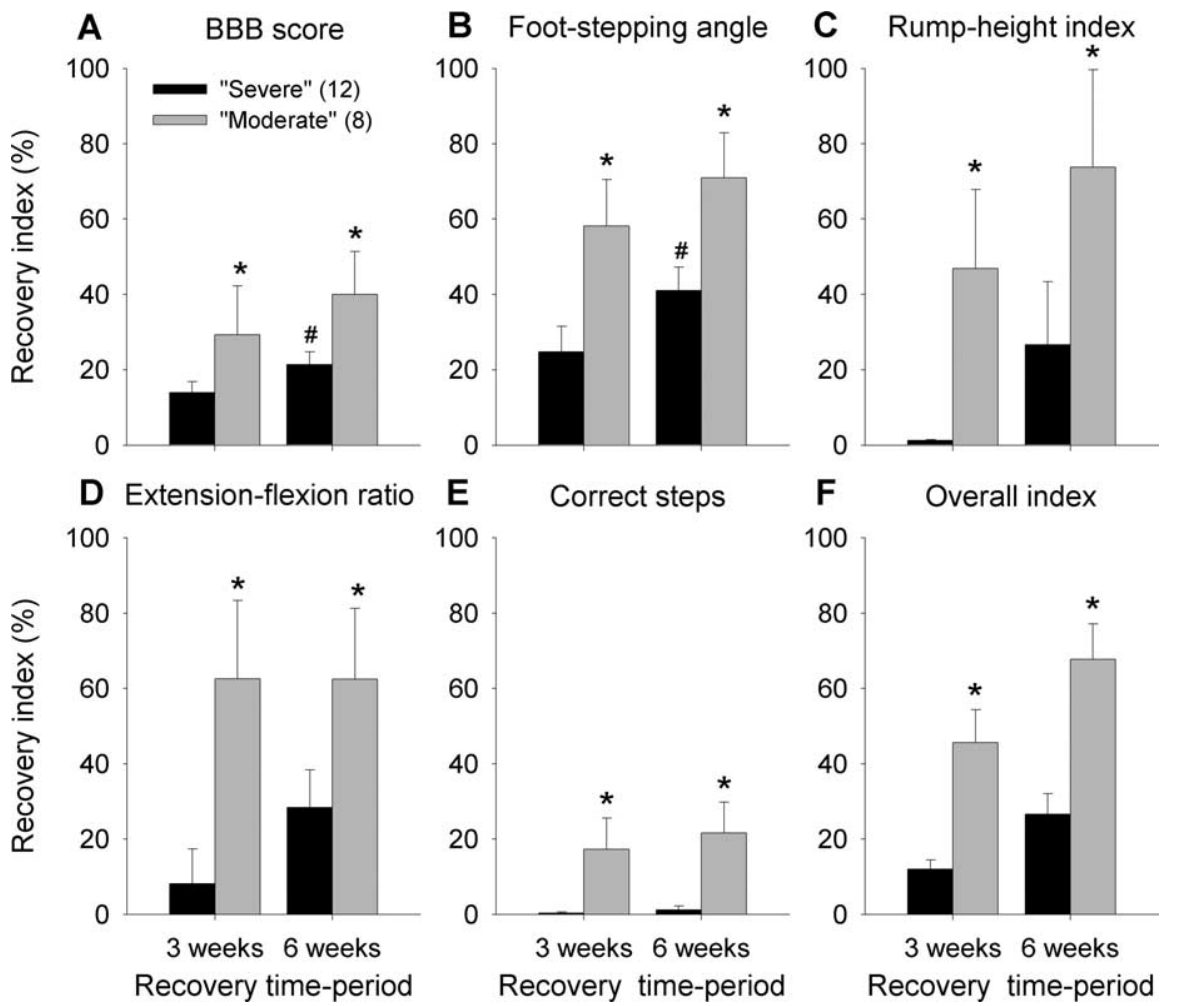

Figure 3. Recovery indices after moderate and severe spinal cord compression in $\mathrm{C} 57 \mathrm{BL} / 6 \mathrm{~J}$ mice. Shown are mean values \pm SEM of individual recovery indices at 3 and 6 weeks after injury calculated for BBB scores $(\boldsymbol{A})$, foot-stepping angles $(\boldsymbol{B})$, rumpheight ratios $(\boldsymbol{C})$, extension-flexion ratios $(\boldsymbol{D})$, and numbers of correct steps $(\boldsymbol{E})$. The mean overall indices shown in $\boldsymbol{F}$ are calculated from individual averaged indices for the parameters shown in $\boldsymbol{A}-\boldsymbol{E}$. Numbers of mice studied per group are given in $\boldsymbol{A}$. Symbols indicate group mean values different from that of severely injured mice $\left(^{*}\right)$ and from the within-group value at 3 weeks $\left({ }^{\#}\right)(p<$ 0.05, one-way ANOVA with Tukey's post hoc test).

\section{Photographic documentation and statistical analysis}

Photographic documentation was made on an Axiophot 2 microscope equipped with a digital camera AxioCam HRC and AxioVision software (Zeiss). Confocal images were obtained on an LSM 510 confocal microscope (Zeiss). The digital images were additionally processed using Adobe Photoshop 8.0 software (Adobe Systems, San Jose, CA).

All numerical data are presented as group mean values with SEM values. Parametric or nonparametric tests ( $t$ test, ANOVA with subsequent Tukey's post hoc tests, or Wilcoxon-Mann-Whitney test) were used for comparisons as appropriate. Nonparametric two-sample Kolmogorov-Smirnov test was applied to compare distributions. Analyses were performed using the Systat 9 software package (SPSS, Chicago, IL). The threshold value for acceptance of differences between groups was $5 \%$. SigmaPlot 8 software (SPSS) was used for regression analyses.

\section{Results}

\section{Evaluation of novel functional parameters}

To validate the novel method for functional analysis, we induced "severe" and "moderate" SCI in two groups of C57BL/6J mice and evaluated their motor performance using both the BBB rating scale (Fig. $2 A$ ) and novel parameters defined in pilot experiments (Fig. $2 B-E$ ). ANOVA for repeated measurements revealed significant effects of time and type of treatment on the BBB score, indicating that the impact of the two injury protocols was different (Fig. 2A-E). Differences between the group mean values were found at all three time points after SCI at which the mice were studied (1,3, and 6 weeks) (Fig. 2A). Compared with the values at $7 \mathrm{~d}$, there was improvement at 3 and 6 weeks after both types of injury. Analysis of the foot-stepping angle, reflecting the ability for plantar stepping and evaluated in a simple two-dimensional model, allowed the same conclusions (Fig. $2 B$ ). The two types of injury produced different degrees of plantar stepping disabilities in the two animal groups, as evaluated 1 week after SCI. Improvement with time was found in both animal groups. Spinal cord injury caused changes in the preoperative values for the other three parameters, but there was no difference between the two groups of mice at $7 \mathrm{~d}$ (Fig. $2 C-E$ ). For the rump-height index, an estimate of the ability for body weight support that requires more complex motor control and coordination compared with plantar placing of the paw, there was no difference between the two groups at later time points (Fig. 2C). The ability to move the limbs without body weight support, evaluated by the extension-flexion ratio, was better in moderately injured mice compared with animals with severe SCI at both 3 and 6 weeks (Fig. 2D). The same was true for numbers of correct steps that the animals made during the most demanding test, ladder climbing, requiring a high degree of supraspinal control and proprioception (Fig. 2E). Thus, the absolute values of the newly defined parameters, with the exception of the rump-height index, showed differences between two groups of mice exposed to injuries of different severity, as was the case for the evaluation according to the $\mathrm{BBB}$ rating scale. Within-group comparisons indicated improvement with time after lesion for the BBB score and the foot-stepping angle but not for the other three parameters. In Figure $2 F$, we show as reference the average time required for climbing up the ladder in the two groups of mice.

We also calculated recovery indices for the parameters shown in Figure $1 A-E$. The mean indices indicated better recovery in moderately compared with severely injured mice at both time periods, 3 and 6 weeks, for all parameters (Fig. $3 A-E$ ). Improvement between 3 and 6 weeks was found only in severely injured mice for the BBB score and for the foot-stepping angle (Fig. $2 A, B)$. Finally, we calculated the overall recovery index from individual mean values for the five different indices (Fig. $3 F$ ). The degree of overall functional improvement was more than twofold higher in moderately injured mice compared with animals with severe SCI.

We introduced the rump-height index as an estimate of the ability to support, in a physiological way, body weight during locomotion. However, apparently spasticity also contributes to the index values to variable degrees in individual animals. Cases in which the mice have high rump height primarily as a result of spasticity can be identified by calculating the product of the rump-height index and the foot-stepping angle. Because the two parameters change in opposite directions 1 week after injury and thereafter (Fig. $2 B, C$ ), the product of the two values should vary within a given range, for example, between 30 and $160^{\circ}$, as can be roughly predicted from mean values at 0 and $7 \mathrm{~d}$. Indeed, for 18 of 20 animals with severe or moderate injury, the index-angle product values were between 28 and $152^{\circ}$ and correlated positively with the foot-stepping angle values $\left(r^{2}=0.89 ; p<0.001\right.$, 
ANOVA) (supplemental Fig. $1 A$, available at www.jneurosci.org as supplemental material). For two mice with severe injury, the product values were very high (235 and $245^{\circ}$ ) (supplemental Fig. $1 \mathrm{~A}$, available at www.jneurosci.org as supplemental material) because of the high position of the rump and abnormally high angle value (toe stepping with strong plantar flexion in the ankle joint) (supplemental Fig. $1 B$, available at www.jneurosci.org as supplemental material).

In a group of $\mathrm{C} 57 \mathrm{BL} / 6 \mathrm{~J}$ mice, we varied the degree of spinal cord compression with the intention to produce lesions of various size. We analyzed these mice functionally and thereafter estimated the scar volume in each mice applying the Cavalieri principle. Nonlinear regression analyses revealed a high degree of covariations between functional estimates and scar volume (Fig. 4A-E). The high degrees of determination $\left(r^{2}\right)$ (Fig. $4 A-E$ ) indicate that between 72 and $87 \%$ of the variability in the functional estimates can be explained by variability in the size of the lesion, an important prerequisite for validation of novel parameters.

\section{Functional recovery of} tenascin-R-deficient mice

Using the parameters described for C57BL/6J mice with severe and moderate SCI, we functionally analyzed $T N R^{-/-}$ and $T N R^{+/+}$mice before and 1, 3, and 6 weeks after severe injury. The preoperative values were similar in the two groups (Fig. $5 A-E$ ), indicating that the tests used in this study are not as stressful or demanding as the rotarod, pole, or wire-hanging tests, conditions under which the motor performance of $T N R^{-1-}$ mice is deficient (Freitag et al., 2003). The degree of impairment found $7 \mathrm{~d}$ after injury was also similar in the two groups for all parameters (Fig. 5A-E). Evaluated using both absolute values and recovery indices for the BBB scores and foot-stepping angles, functional recovery at 3 and 6 weeks after SCI was better in $T N R^{-1-}$ mice compared with wild-type littermates (Figs. 5A, $B$, $6 A, B$, respectively). For the other three parameters, however, no differences in the outcome of SCI between the two animal groups were found (Figs. 5C-E, 6C,D). The overall recovery indices were significantly better in $T N R^{-1-}$ compared with $T_{N R}{ }^{+/+}$mice (Fig. $6 E, F$ ). As a reference, the mean duration of ladder climbing before and after operation is shown for the two groups of mice in Figure $5 F$. TNR ${ }^{-/-}$ were slower in climbing the ladder at $7 \mathrm{~d}$ after injury, but this is probably not di-
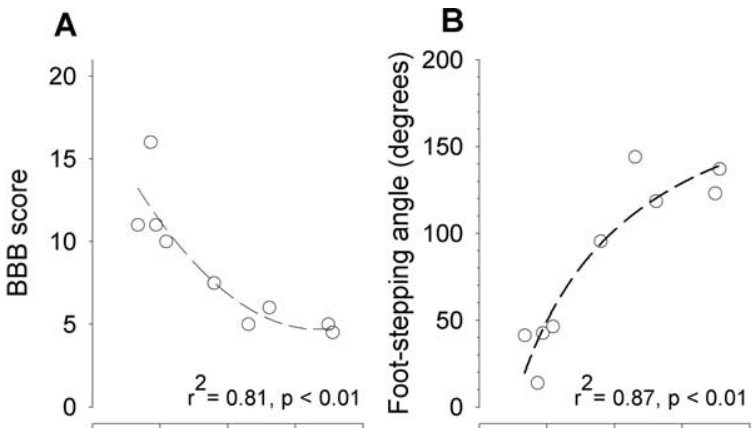

E

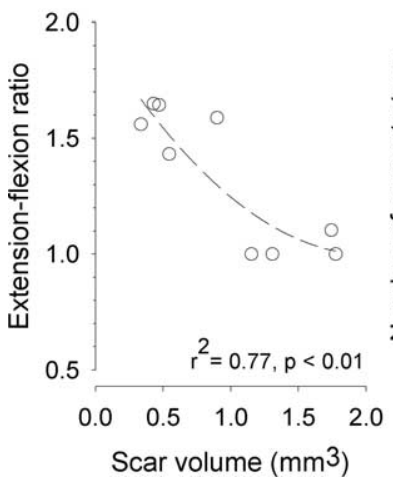

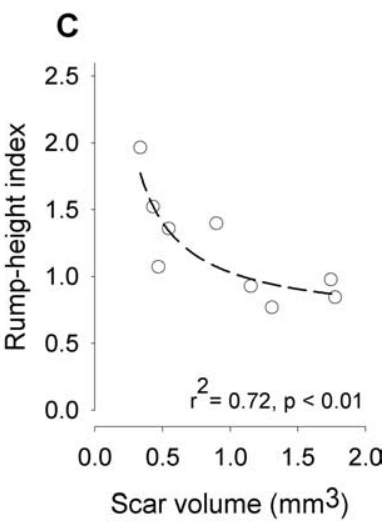

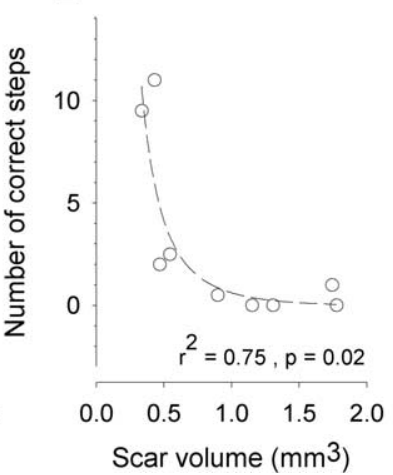

Figure 4. Correlations between functional parameters and scar volume in $(57 B L / 6 \mathrm{~J}$ mice. $\boldsymbol{A}-\boldsymbol{E}$, Scatter plots of individual values for BBB score $(\boldsymbol{A})$, foot-stepping angle $(\boldsymbol{B})$, rump-height index $(\boldsymbol{C})$, extension-flexion ratio $(\boldsymbol{D})$, and number of correct steps $(\boldsymbol{E})$ with regression lines, coefficients of determination $\left(r^{2}\right)$, and ANOVA probability values $(p)$ calculated by nonlinear regression analyses. During spinal cord injury, compression forces of 50,75 , or $100 \%$ of maximum were applied in individual mice to produce different degrees of lesion within this animal group. Scar volume was estimated from spaced serial sections using the Cavalieri principle.
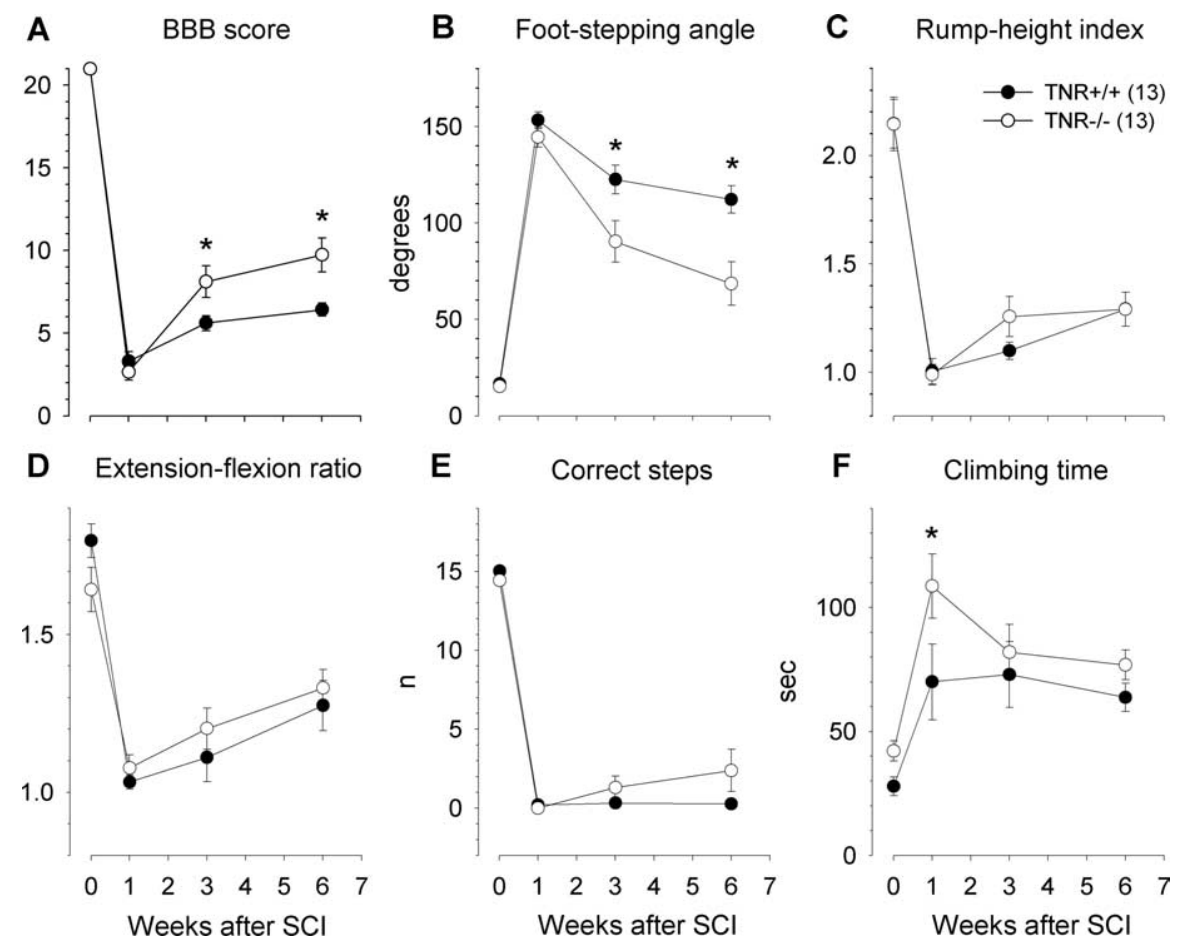

Figure 5. Time course and degree of functional recovery in TNR-deficient $\left(\operatorname{TNR}^{-/-}\right)$mice and wild-type $\left(\operatorname{TNR}^{+/+}\right)$littermates after severe spinal cord compression. Shown are mean values \pm SEM of open-field locomotion (BBB) scores $(\boldsymbol{A})$, foot-stepping angles $(\boldsymbol{B})$, rump-height indices $(\boldsymbol{C})$, extension-flexion ratios $(\boldsymbol{D})$, numbers of correct steps $(\boldsymbol{E})$, and ladder-climbing time $(\boldsymbol{F})$ before surgery (day 0 ) and at 1,3 , and 6 weeks after injury. Numbers of mice studied per group are given in $\boldsymbol{C}$. Asterisks indicate significant differences between group mean values at a given time period ( $p<0.05$, one-way ANOVA for repeated measurements with Tukey's post hoc test). 

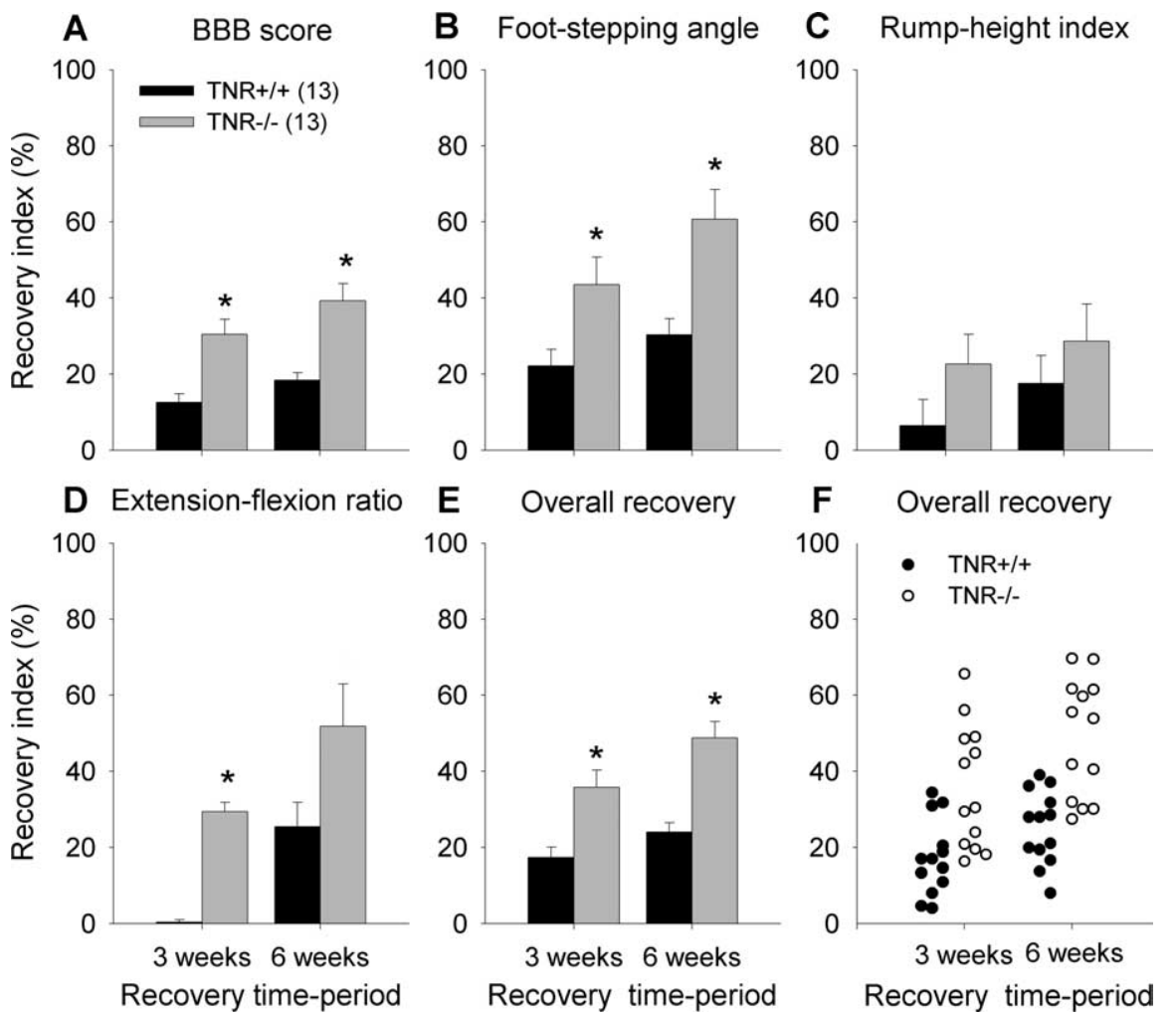

Figure 6. Recovery indices in $T N R^{-/-}$and $T N R^{+/+}$mice. Shown are mean values \pm SEM of individual recovery indices at 3 and 6 weeks after injury calculated for BBB scores $(\boldsymbol{A})$, foot-stepping angles $(\boldsymbol{B})$, rump-height ratios $(\boldsymbol{C})$, and extension-flexion ratios $(\boldsymbol{D})$. Group mean values and individual values of overall recovery indices (calculated as means of the values for the parameters shown in $\boldsymbol{A}-\boldsymbol{D}$ ) are shown in $\boldsymbol{E}$ and $\boldsymbol{F}$, respectively. Numbers of mice studied per group are given in $\boldsymbol{A}$. Asterisks indicate values different from that of $T N C^{+/+}$mice ( $p<0.05$, one-way ANOVA with Tukey's post hoc test).

rectly related to motor impairment, which appeared similar as evaluated by the other functional parameters in the two genotype groups of mice.

\section{Structural correlates of enhanced functional recovery}

We analyzed the descending connections, posttraumatically preserved or reestablished, from the cervical spinal cord, the reticular formation, the raphe nuclei, and the red nucleus to the lumbar spinal cord in $T N R^{-/-}$and $T N R^{+/+}$mice at 6 weeks after the compression injury. Neurons projecting axons beyond the lesion site were retrogradely labeled in a second operation. Tracer (Fluoro-Gold) was applied after a complete transection of the spinal cord one segment caudally from the site of compression. Retrogradely labeled cell bodies, analyzed in $250-\mu \mathrm{m}$-spaced serial sections through the analyzed regions, were found in all mice studied with the exception of the motor cortex in five of six $T N R^{+/+}$mice and four of six $T N R^{-/-}$animals. Quantitative analysis revealed similar bilateral numbers of labeled cell profiles in the two groups of mice for all regions studied (Fig. 7).

We also counted numbers of catecholaminergic [TH-positive $\left.\left(\mathrm{TH}^{+}\right)\right]$and serotonergic $\left(5-\mathrm{HT}-\mathrm{T}^{+}\right)$axons projecting beyond an arbitrarily selected border $250 \mu \mathrm{m}$ caudally to the lesion site in spaced serial parasagittal sections. Similar numbers of immunolabeled fibers, spared or regenerated after injury, were found to cross the border in the two groups of mice $(4.0 \pm 1.7$ vs $5.4 \pm 1.9$ and $34 \pm 9.0$ vs $23 \pm 2.7 \mathrm{TH}^{+}$and $5-\mathrm{HT}_{-} \mathrm{T}^{+}$axons in $\mathrm{TNR}^{+/+}$vs $T N R^{-1-}$ mice, respectively; $p>0.05$, Wilcoxon-Mann-Whitney test).
Analyses of motoneuron soma size and synaptic inputs

Mean areas of motoneuron somata calculated from individual animal mean values were similar in intact and lesioned spinal cords of both $T N R^{-/-}$and $T N R^{+/+}$mice (Fig. $8 D$ ). Analysis of frequency distributions revealed that similar fractions of the motoneurons in injured spinal cords of $T N R^{-/-}$and $T N R^{+/+}$mice were atrophic (supplemental Fig. 2A, available at www. jneurosci.org as supplemental material). Atrophic $\mathrm{ChAT}^{+}$cell bodies were seen mostly in confocal image stacks taken from the ventral horn in the immediate vicinity of the lesion site (data not shown). The density (number per unit length) of large perisomatic $\mathrm{ChAT}^{+}$boutons (Fig. $8 A$ ), known to form C-type synapses on motoneurons associated with muscarinic type 2 receptors (Davidoff and Irintchev, 1986; Hellström et al., 2003), was dramatically reduced after injury in mice of both genotypes (Fig. 8E) (supplemental Fig. $2 B$, available at www.jneurosci.org as supplemental material). Importantly, coverage of somata by cholinergic boutons was significantly lower in intact spinal cords of $T N R^{-/-}$mice compared with wild-type littermates (Fig. 8E) (supplemental Fig. $2 B$, available at www.jneurosci.org as supplemental material).

Perisomatic densities of $\mathrm{VGAT}^{+}$ puncta reflect numbers of GABAergic synapses on the cell bodies (Nikonenko et al., 2006). GABAergic coverage of motoneuron somata, identified by their size and location in the spinal cord (Fig. $8 B$ ), was lower in intact $T N R^{-1-}$ mice compared with intact $T_{N R}^{+/+}$littermates (Fig. $8 F$ ) (supplemental Fig. 2C, available at www.jneurosci.org as supplemental material). Spinal cord injury did not affect this coverage in $T N R^{+/+}$mice but caused an increase in $T N R^{-1-}$ mice compared with intact genotypematched animals (Fig. $8 F$ ) (supplemental Fig. $2 C$, available at www.jneurosci.org as supplemental material). Glutamatergic $\left(\right.$ VGLUT1 $^{+}$) puncta around cell bodies (Fig. 8C) might be terminals forming axo-somatic or axo-dendritic synapses. Similar to $\mathrm{VGAT}^{+}$puncta, the density of these terminals was not changed after SCI in $T_{N R}^{+/+}$mice (Fig. 8G) (supplemental Fig. 2D, available at www.jneurosci.org as supplemental material). In contrast to the GABAergic terminals, however, numbers of VGLUT1 $^{+}$puncta were increased in intact $T N R^{-1-}$ mice, and injury caused a reduction in their density (Fig. 8G) (supplemental Fig. 2D, available at www.jneurosci.org as supplemental material). The genotype-related differences observed for densities of perisomatic puncta can be related to the absence of TNR in perineuronal nets in $T N R^{-/-}$ mice as opposed to TNR expression in both intact and injured wild-type mice (Rollenhagen et al., 2001; Murakami and Ohtsuka, 2003; present study). The differences may alternatively be related to disorganization of perineuronal nets in the spinal cord as reported previously for perineuronal nets in the hippocampus of TNR-deficient mice (Weber et al., 1999). 


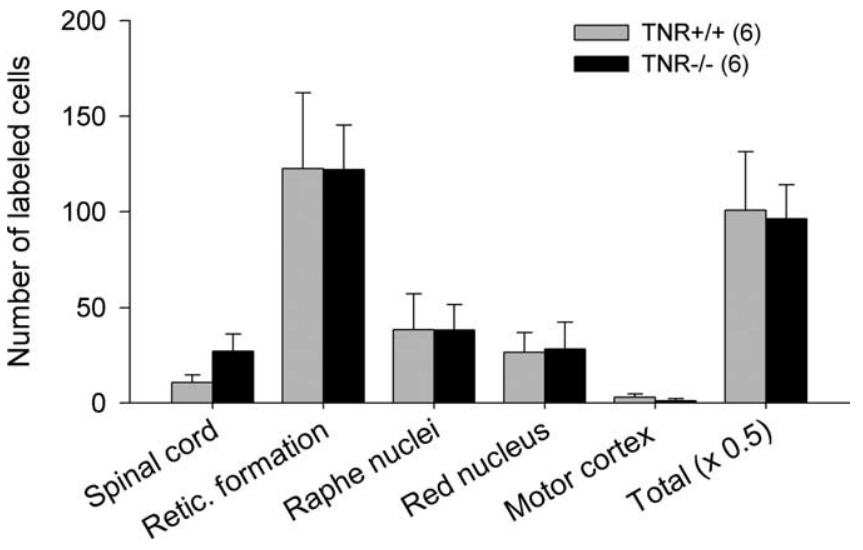

Figure 7. Neurons projecting beyond the lesion site in $T N R^{-/-}$and $T N R^{+/+}$mice. Shown are mean \pm SEM numbers of labeled neuronal cell profiles seen in the cervical spinal cord and different brain areas in spaced serial sections $250 \mu \mathrm{m}$ apart 2 weeks after application of tracer caudal to the lesion site. Numbers of mice studied per group are given in parentheses at the top. No differences between the group mean values were observed ( $p>0.05$, two-sided $t$ test for independent samples).

\section{Perineuronal nets in the intact and injured spinal cord} In intact spinal cords of both $T N R^{-/-}$and $T N R^{+/+}$mice, WFA staining visualized perineuronal nets around motoneurons and interneurons. Staining intensity was medium to low in motoneurons and high in interneurons in both genotypes, and it appeared generally weaker in $T N R^{-/-}$mice compared with $T N R^{+/+}$littermates. Perineuronal nets in $T N R^{-/-}$mice were disorganized in a manner similar to that reported previously for nets in the hippocampus (Weber et al., 1999) (supplemental Fig. $3 A, B$, available at www.jneurosci.org as supplemental material). One to 6 weeks after spinal cord injury, the genotype-specific pattern of staining throughout the lumbar spinal cord was preserved. WFAstained cells were seen even in close vicinity $(<500 \mu \mathrm{m})$ of the lesion scar (supplemental Fig. 3C,D, available at www.jneurosci. org as supplemental material). Immunofluorescence stainings with a monoclonal antibody revealed that TNR is detectable in perineuronal nets in both lesioned and intact spinal cords of $T N R^{+/+}$mice but not of $T N R^{-/-}$mice (supplemental Fig. $3 E, F$, available at www.jneurosci.org as supplemental material). Our observations indicate that spinal cord injury does not lead to decomposition of perineuronal nets and, in wild-type mice, to loss of TNR from the extracellular matrix around motoneurons and interneurons. These findings are important with regard to new observations that, after focal cerebral ischemia, decomposition and reduced expression of extracellular matrix proteins develop in perineuronal nets around neocortical and thalamic neurons both in the peri-infarct and remote regions (Hobohm et al., 2005).

\section{Discussion}

The results of this study provide evidence that TNR is a molecule restricting recovery from spinal cord injury in the adult mouse. Applying established and novel measures of the functional outcome after compression injury, we demonstrate that TNRdeficient mice recover better compared with wild-type littermates. Morphological data suggest that enhanced functional improvement is related to enhanced posttraumatic rearrangement of synaptic connections.

\section{Novel estimates of motor functional abilities}

The current standard for evaluation of motor behavior in rats and mice is the BBB rating scale for open-field locomotion (Basso et al., 1995). Modifications of the scale for mice have been published recently (Joshi and Fehlings, 2002; Engesser-Cesar et al., 2005; Li et al., 2006). Researchers are unanimous that the rating method has limitations (Basso et al., 1996; Kesslak and Keirstead, 2003; Basso, 2004; Fouad and Pearson, 2004). A variety of other methods, such as kinematic analysis, walking on a grid, inclined plane or narrow beam, measurements of ground reaction force patterns, and walking-track analysis, have been proposed and used (Kesslak and Keirstead, 2003; Fouad and Pearson, 2004). None of these methods has proven to be superior to locomotor rating and been established as a standard.

Here we report a novel objective approach for reliable assessment of defined aspects of motor performance depending on different degrees on supraspinal control (Edgerton et al., 2004; Fouad and Pearson, 2004). Changes in each of the four parameters evaluated are strongly dependent on the amount of induced tissue damage. The covariations of the functional parameters and the scar volume are best described by nonlinear regression models as reported previously, and also confirmed here, for the BBB score (Kloos et al., 2005). The method produces numerical data and requires neither special knowledge nor sophisticated equipment. The use of a battery of four parameters increases the reliability of the conclusions drawn. The new approach has advantages, which, however, does not mean that other tests will become needless. We consider that the new evaluation approach should be supplemented, as done in this study, with methods widely used for functional analyses in rodents in the recent years so that a basis for comparisons with previous studies is provided. Particularly advisable is to continue the usage of locomotor rating scales, not least because they allow assessment of motor disabilities in a personalized and clinically customary manner.

\section{Enhanced recovery in TNR-deficient mice}

As estimated by an overall index, TNR-deficient mice recovered better than wild-type control mice within 6 weeks after spinal cord compression. Absence of TNR in the injured spinal cord provides advantages for recovery. Three lines of evidence indicate that the better outcome in $T N R^{-/-}$compared with $T N R^{+/+}$mice is not related to enhanced axonal regeneration across the injured site or to greater tissue sparing. The degree of functional impairment, apparently correlated with the amount of induced tissue damage, was similar in the two genotype groups at 1 week after lesion. Numbers of catecholaminergic and serotonergic fibers present distal to the lesion scar at 6 weeks were also similar in TNR-deficient mice and wild-type littermates. The same was true, as revealed by retrograde labeling, for the degree of preservation and reestablishment of descending projections to the lumbar spinal cord. Therefore, we cannot attribute better recovery to enhanced axonal regrowth in the absence of TNR as could be expected considering that it inhibits neurite outgrowth when present as a sharp border with a conducive substrate in vitro (Pesheva et al., 1993; Taylor et al., 1993; Xiao et al., 1997; Becker et al., 2000). This conclusion is supported by the finding that functions requiring high level of supraspinal control were not better in $T N R^{-/-}$mice compared with $T N R^{+/+}$mice at 3 and 6 weeks after lesion. Therefore, we assume that lack of TNR has an impact on local adaptive responses in the injured spinal cord.

\section{Possible mechanisms of enhanced recovery}

TNR is expressed by motoneurons and interneurons in the intact and injured spinal cord and accumulates in the perineuronal nets surrounding these neurons (Rollenhagen et al., 2001; Murakami and Ohtsuka, 2003; present study). Ablation of TNR expression 

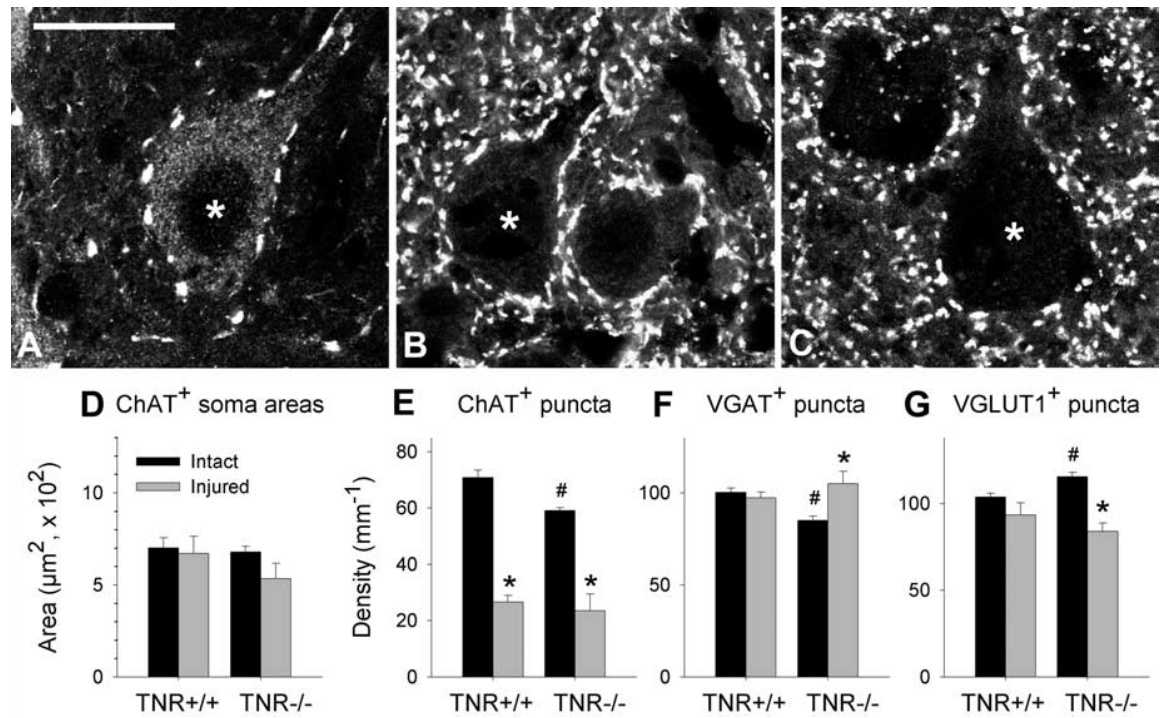

Figure 8. Analysis of perisomatic puncta. Confocal images (1- $\mu$ m-thick optical slices) show the appearance of $\mathrm{ChAT}^{+}(\boldsymbol{A})$, VGAT $^{+}(\boldsymbol{B})$, and VGLUT1 ${ }^{+}(\boldsymbol{C})$ puncta around motoneuron cell bodies (asterisks) in sections from intact TNR ${ }^{-/-}(\boldsymbol{A})$ and TNR ${ }^{+/+}$ $(\boldsymbol{B}, \boldsymbol{C})$ mice. Scale bar: $\boldsymbol{A}-\boldsymbol{C}, 25 \mu \mathrm{m} . \boldsymbol{D}-\mathbf{G}$, Soma area of ChAT ${ }^{+}$motoneurons $(\boldsymbol{D})$ and linear densities of $\mathrm{ChAT}^{+}(\boldsymbol{E}), \mathrm{VGAT}^{+}(\boldsymbol{F})$, and VGLUT1 ${ }^{+}(\boldsymbol{G})$ puncta surrounding motoneurons identified by ChAT staining $(\boldsymbol{A})$ or by size of the cell somata $(\boldsymbol{B}, \boldsymbol{C})$ and nuclei (data not shown). Shown are group mean \pm SEM values calculated from individual mean values. The numbers of injured/intact $T N R^{-/-}$and $T N R^{+/+}$mice studied were six/four and four/four, respectively. Between 110 and 160 cells were analyzed per group and parameter. Symbols indicate group mean values significantly different from intact animals of the same genotype $\left({ }^{*}\right)$ or from intact $T N R^{+/+}$mice $\left(^{\#}\right)(p<0.05$, two-sided $t$ test for independent samples, degrees of freedom determined by the number of mice studied).

in mice results in disorganization of the perineuronal nets in the brain and spinal cord (Weber et al., 1999; Brückner et al., 2000; present study). TNR is also essential for maintenance of normal perisomatic inhibitory input to CA1 pyramidal neurons (Nikonenko et al., 2003). Therefore, it appears reasonable that the observed impact of TNR deficiency on recovery from spinal cord injury is, at least in part, related to alterations in synaptic inputs to motoneurons. Evaluation of perisomatic puncta densities provided evidence supporting this idea. In the intact spinal cord of TNR-deficient mice, density of GABAergic puncta, which reflects the number of perisomatic inhibitory synapses (Nikonenko et al., 2006), were reduced compared with wild-type control mice. Thus, similar to the hippocampus, TNR deficiency leads to reduced inhibitory input to motoneurons. Also, numbers of cholinergic synaptic boutons were lower in the $T N R^{-/-}$mice. The origin and function of these synapses are not precisely known. A recent study has shown that these muscarinergic synapses modulate several ionic conductances responsible for repetitive discharges of motoneurons (Chevallier et al., 2006). Finally, numbers of glutamatergic synaptic terminals around motoneuron perikarya, forming axo-somatic and/or axo-dendritic synapses, were reduced in the intact spinal cord of $T N R^{-/-}$mice compared with $T N R^{+/+}$littermates. Altogether, these aberrations in synaptic inputs might be interpreted as an indication for a misbalance between excitation and inhibition in the spinal cord of $T N R^{-1-}$ mice. Reduced inhibition and enhanced excitatory transmission have been well documented for the hippocampus of $T N R^{-1-}$ mice (Saghatelyan et al., 2001). The functional consequences of these abnormalities are impairments in long-term potentiation in the hippocampus and cortical and hippocampal neuronal hyperexcitability (Saghatelyan et al., 2000, 2001; Brenneke et al., 2004; Gurevicius et al., 2004). The abnormalities found in the intact spinal cord may contribute to motor impairments of $T N R^{-/-}$mice that become apparent under demanding condi-

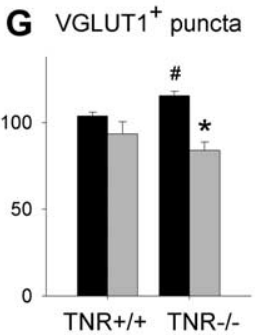

tions, such as rotarod, pole, and wirehanging tests (Freitag et al., 2003), but are not detectable in less stressful and challenging tests as those used here for analysis of motor functions.

Previous studies have shown that spinal cord injury causes an acute loss of motoneuron perisomatic terminals, which is gradually reversed in chronic paraplegic rats (Nacimiento et al., 1995). In wild-type mice studied 6 weeks after injury, densities of GABAergic terminals were similar to intact mice, suggesting that this local input is not changed after injury or is normalized during the recovery period. However, there was a dramatic loss of cholinergic perisomatic terminals. This finding suggests that this input is, in part, of supraspinal or propriospinal origins (Rekling et al., 2000). Loss of muscarinic modulation at motoneuron cell bodies might contribute to the alterations in motoneuronal excitability known to occur after lesion. Similar to $\mathrm{TNR}^{+/+}$mice, loss of cholinergic terminals was found in $T N R^{-/-}$mice. Relative to intact animals, the loss of such terminals was smaller in $T N R^{-/-}$compared with $T N R^{+/+}$mice. In contrast to $T N R^{+/+}$ littermates, there was an increase of GABAergic and reduction of glutamatergic terminals in injured compared with intact $T N R^{-/-}$mice. Thus, absence of TNR in the injured spinal cord leads to enhanced reorganization of synaptic inputs favoring motoneuron inhibition. Chronic paraplegia is characterized by enhanced excitability, which is manifested as involuntary muscle contractions and spasticity and is related to increased excitatory spinal reflex input, decreased segmental and descending inhibition, and increased excitability of motoneurons (Li et al., 2004). It is conceivable that hyperexcitability can more effectively be counteracted by an inhibition-favoring constellation of the perisomatic inputs to motoneurons. Considering the fact that relatively low numbers of inhibitory perisomatic synapses efficiently filter dendrite-originating excitatory signals just before they reach the action potential-trigger zone, the axon hillock, it can be assumed that even a moderate enhancement of perisomatic inhibition will have markedly positive physiological consequences. In line with these considerations is the finding that development of spasticity after sacral spinal cord transection in rats goes in parallel with loss of modulatory cholinergic boutons and increase in excitatory VGLUT2-positive terminals on sacrocaudal motoneurons (Kitzman, 2006). Enhanced structural plasticity may also contribute to the better functional outcome of facial nerve repair in $T N R^{-/-}$mice (Guntinas-Lichius et al., 2005). Improved recovery from spinal cord injury after application of chondroitinase ABC (Bradbury et al., 2002) is possibly also attributable to enzymatic degradation of the perineuronal nets and concomitant removal of axon growth-inhibiting molecules such as chondroitin sulfate proteoglycans and TNR (Rhodes and Fawcett, 2004). Finally, enzymatic digestion of perineuronal nets in the adult visual cortex enables reactivation of experience-dependent plasticity (Pizzorusso et al., 2002). However, because TNR and other associated molecules of the extracellular matrix are not only detectable in perineuronal nets but are localized more widely in brain and spinal cord, other molec- 
ular and cellular mechanisms underlying TNR functions are conceivable. In particular, the contribution of reduced axon conduction velocity of myelinated tracts (Weber et al., 1999) to enhanced recovery of function remain unknown. Presently, our findings indicate that perineuronal net components are considerable contributors to the poor outcome of spinal cord injury in adult rodents, together with and possibly via different mechanisms compared with other inhibitory molecules such as Nogo-A, myelin-associated glycoprotein, and other molecules (Buchli and Schwab, 2005).

In conclusion, the results of this study demonstrate that TNR is among the molecules restricting functional improvement after spinal cord injury in mice. Additional investigations into the mechanisms of this inhibition will provide valuable insights into the pathophysiology of paraplegia.

\section{References}

Angelov DN, Walther M, Streppel M, Guntinas-Lichius O, Neiss WF, Probstmeier R, Pesheva P (1998) Tenascin-R is antiadhesive for activated microglia that induce downregulation of the protein after peripheral nerve injury: a new role in neuronal protection. J Neurosci 18:6218-6229.

Basso DM (2004) Behavioral testing after spinal cord injury: congruities, complexities, and controversies. J Neurotrauma 21:395-404.

Basso DM, Beattie MS, Bresnahan JC (1995) A sensitive and reliable locomotor rating scale for open field testing in rats. J Neurotrauma 12:1-21.

Basso DM, Beattie MS, Bresnahan JC, Anderson DK, Faden AI, Gruner JA, Holford TR, Hsu CY, Noble LJ, Nockels R, Perot PL, Salzman SK, Young W (1996) MASCIS evaluation of open field locomotor scores: effects of experience and teamwork on reliability. Multicenter Animal Spinal Cord Injury Study. J Neurotrauma 13:343-359.

Becker CG, Becker T, Meyer RL, Schachner M (1999) Tenascin-R inhibits the growth of optic fibers in vitro but is rapidly eliminated during nerve regeneration in the salamander Pleurodeles waltl. J Neurosci 19:813-827.

Becker CG, Schweitzer J, Feldner J, Becker T, Schachner M (2003) Tenascin- $\mathrm{R}$ as a repellent guidance molecule for developing optic axons in zebrafish. J Neurosci 23:6232-6237.

Becker CG, Schweitzer J, Feldner J, Schachner M, Becker T (2004) Tenascin- $\mathrm{R}$ as a repellent guidance molecule for newly growing and regenerating optic axons in adult zebrafish. Mol Cell Neurosci 26:376-389.

Becker T, Anliker B, Becker CG, Taylor J, Schachner M, Meyer RL, Bartsch U (2000) Tenascin-R inhibits regrowth of optic fibers in vitro and persists in the optic nerve of mice after injury. Glia 29:330-346.

Bradbury EJ, Moon LD, Popat RJ, King VR, Bennett GS, Patel PN, Fawcett JW, McMahon SB (2002) Chondroitinase ABC promotes functional recovery after spinal cord injury. Nature 416:636-640.

Brenneke F, Bukalo O, Dityatev A, Lie AA (2004) Mice deficient for the extracellular matrix glycoprotein tenascin-R show physiological and structural hallmarks of increased hippocampal excitability, but no increased susceptibility to seizures in the pilocarpine model of epilepsy. Neuroscience 124:841-855.

Brückner G, Grosche J, Schmidt S, Hartig W, Margolis RU, Delpech B, Seidenbecher CI, Czaniera R, Schachner M (2000) Postnatal development of perineuronal nets in wild-type mice and in a mutant deficient in tenascin-R. J Comp Neurol 428:616-629.

Buchli AD, Schwab ME (2005) Inhibition of Nogo: a key strategy to increase regeneration, plasticity and functional recovery of the lesioned central nervous system. Ann Med 37:556-567.

Bukalo O, Schachner M, Dityatev A (2001) Modification of extracellular matrix by enzymatic removal of chondroitin sulfate and by lack of tenascin-R differentially affects several forms of synaptic plasticity in the hippocampus. Neuroscience 104:359-369.

Chevallier S, Nagy F, Cabelguen JM (2006) Cholinergic control of excitability of spinal motoneurones in the salamander. J Physiol (Lond) 570:525540.

Curtis R, Green D, Lindsay RM, Wilkin GP (1993) Up-regulation of GAP-43 and growth of axons in rat spinal cord after compression injury. J Neurocytol 22:51-64.

Davidoff MS, Irintchev AP (1986) Acetylcholinesterase activity and type C synapses in the hypoglossal, facial and spinal-cord motor nuclei of rats. An electron-microscope study. Histochemistry 84:515-524.
Deckner M, Lindholm T, Cullheim S, Risling M (2000) Differential expression of tenascin-C, tenascin- $\mathrm{R}$, tenascin/J1, and tenascin-X in spinal cord scar tissue and in the olfactory system. Exp Neurol 166:350-362.

Dityatev A, Schachner M (2003) Extracellular matrix molecules and synaptic plasticity. Nat Rev Neurosci 4:456-468.

Edgerton VR, Tillakaratne NJ, Bigbee AJ, de Leon RD, Roy RR (2004) Plasticity of the spinal neural circuitry after injury. Annu Rev Neurosci 27:145-167.

Engesser-Cesar C, Anderson AJ, Basso DM, Edgerton VR, Cotman CW (2005) Voluntary wheel running improves recovery from a moderate spinal cord injury. J Neurotrauma 22:157-171.

Fouad K, Pearson K (2004) Restoring walking after spinal cord injury. Prog Neurobiol 73:107-126.

Freitag S, Schachner M, Morellini F (2003) Behavioral alterations in mice deficient for the extracellular matrix glycoprotein tenascin-R. Behav Brain Res 145:189-207.

Guntinas-Lichius O, Angelov DN, Morellini F, Lenzen M, Skouras E, Schachner M, Irintchev A (2005) Opposite impacts of tenascin-C and tenascin-R deficiency in mice on the functional outcome of facial nerve repair. Eur J Neurosci 22:2171-2179.

Gurevicius K, Gureviciene I, Valjakka A, Schachner M, Tanila H (2004) Enhanced cortical and hippocampal neuronal excitability in mice deficient in the extracellular matrix glycoprotein tenascin-R. Mol Cell Neurosci 25:515-523.

Hellström J, Oliveira AL, Meister B, Cullheim S (2003) Large cholinergic nerve terminals on subsets of motoneurons and their relation to muscarinic receptor type 2. J Comp Neurol 460:476-486.

Hobohm C, Gunther A, Grosche J, Rossner S, Schneider D, Bruckner G (2005) Decomposition and long-lasting downregulation of extracellular matrix in perineuronal nets induced by focal cerebral ischemia in rats. J Neurosci Res 80:539-548.

Irintchev A, Rollenhagen A, Troncoso E, Kiss JZ, Schachner M (2005a) Structural and functional aberrations in the cerebral cortex of tenascin- $\mathrm{C}$ deficient mice. Cereb Cortex 15:950-962.

Irintchev A, Simova O, Eberhardt KA, Morellini F, Schachner M (2005b) Impacts of lesion severity and TrkB deficiency on functional outcome of femoral nerve injury assessed by a novel single-frame motion analysis in mice. Eur J Neurosci 22:802-808.

Jiao Y, Sun Z, Lee T, Fusco FR, Kimble TD, Meade CA, Cuthbertson S, Reiner A (1999) A simple and sensitive antigen retrieval method for freefloating and slide-mounted tissue sections. J Neurosci Methods 93:149-162.

Joshi M, Fehlings MG (2002) Development and characterization of a novel, graded model of clip compressive spinal cord injury in the mouse. 1. Clip design, behavioral outcomes, and histopathology. J Neurotrauma 19:175-190.

Kesslak JP, Keirstead HS (2003) Assessment of behavior in animal models of spinal cord injury. J Spinal Cord Med 26:323-328.

Kitzman P (2006) Changes in vesicular glutamate transporter 2, vesicular GABA transporter and vesicular acetylcholine transporter labeling of sacrocaudal motoneurons in the spastic rat. Exp Neurol 197:407-419.

Kloos AD, Fisher LC, Detloff MR, Hassenzahl DL, Basso DM (2005) Stepwise motor and all-or-none sensory recovery is associated with nonlinear sparing after incremental spinal cord injury in rats. Exp Neurol 191:251-265.

Li Y, Gorassini MA, Bennett DJ (2004) Role of persistent sodium and calcium currents in motoneuron firing and spasticity in chronic spinal rats. J Neurophysiol 91:767-783.

Li Y, Oskouian RJ, Day YJ, Kern JA, Linden J (2006) Optimization of a mouse locomotor rating system to evaluate compression-induced spinal cord injury: correlation of locomotor and morphological injury indices. J Neurosurg Spine 4:165-173.

Liao H, Bu WY, Wang TH, Ahmed S, Xiao ZC (2005) Tenascin-R plays a role in neuroprotection via its distinct domains that coordinate to modulate the microglia function. J Biol Chem 280:8316-8323.

Metz GA, Merkler D, Dietz V, Schwab ME, Fouad K (2000) Efficient testing of motor function in spinal cord injured rats. Brain Res 883:165-177.

Morganti MC, Taylor J, Pesheva P, Schachner M (1990) Oligodendrocytederived J1-160/180 extracellular matrix glycoproteins are adhesive or repulsive depending on the partner cell type and time of interaction. Exp Neurol 109:98-110. 
Murakami T, Ohtsuka A (2003) Perisynaptic barrier of proteoglycans in the mature brain and spinal cord. Arch Histol Cytol 66:195-207.

Nacimiento W, Sappok T, Brook GA, Toth L, Schoen SW, Noth J, Kreutzberg GW (1995) Structural changes of anterior horn neurons and their synaptic input caudal to a low thoracic spinal cord hemisection in the adult rat: a light and electron microscopic study. Acta Neuropathol (Berl) 90:552-564.

Nikonenko A, Schmidt S, Skibo G, Bruckner G, Schachner M (2003) Tenascin-R-deficient mice show structural alterations of symmetric perisomatic synapses in the CA1 region of the hippocampus. J Comp Neurol 456:338-349.

Nikonenko AG, Sun M, Lepsveridze E, Apostolova I, Petrova I, Irintchev A, Dityatev A, Schachner M (2006) Enhanced perisomatic inhibition and impaired long-term potentiation in the CA1 region of juvenile CHL1 deficient mice. Eur J Neurosci 23:1839-1852.

Pesheva P, Gennarini G, Goridis C, Schachner M (1993) The F3/11 cell adhesion molecule mediates the repulsion of neurons by the extracellular matrix glycoprotein J1-160/180. Neuron 10:69-82.

Pesheva P, Probstmeier R (2000) The yin and yang of tenascin-R in CNS development and pathology. Prog Neurobiol 61:465-493.

Pizzorusso T, Medini P, Berardi N, Chierzi S, Fawcett JW, Maffei L (2002) Reactivation of ocular dominance plasticity in the adult visual cortex. Science 298:1248-1251.

Rekling JC, Funk GD, Bayliss DA, Dong XW, Feldman JL (2000) Synaptic control of motoneuronal excitability. Physiol Rev 80:767-852.

Rhodes KE, Fawcett JW (2004) Chondroitin sulphate proteoglycans: preventing plasticity or protecting the CNS? J Anat 204:33-48.

Rollenhagen A, Czaniera R, Albert M, Wintergerst ES, Schachner M (2001) Immunocytological localization of the HNK-1 carbohydrate in murine cerebellum, hippocampus and spinal cord using monoclonal antibodies with different epitope specificities. J Neurocytol 30:337-351.

Saghatelyan AK, Gorissen S, Albert M, Hertlein B, Schachner M, Dityatev A (2000) The extracellular matrix molecule tenascin-R and its HNK-1 carbohydrate modulate perisomatic inhibition and long-term potentiation in the CA1 region of the hippocampus. Eur J Neurosci 12:3331-3342.
Saghatelyan AK, Dityatev A, Schmidt S, Schuster T, Bartsch U, Schachner M (2001) Reduced perisomatic inhibition, increased excitatory transmission, and impaired long-term potentiation in mice deficient for the extracellular matrix glycoprotein tenascin-R. Mol Cell Neurosci 17:226-240.

Sandvig A, Berry M, Barrett LB, Butt A, Logan A (2004) Myelin-, reactive glia-, and scar-derived CNS axon growth inhibitors: expression, receptor signaling, and correlation with axon regeneration. Glia 46:225-251.

Schachner M (1997) Neural recognition molecules and synaptic plasticity. Curr Opin Cell Biol 9:627-634.

Soblosky JS, Colgin LL, Chorney-Lane D, Davidson JF, Carey ME (1997) Ladder beam and camera video recording system for evaluating forelimb and hindlimb deficits after sensorimotor cortex injury in rats. J Neurosci Methods 78:75-83.

Srinivasan J, Schachner M, Catterall WA (1998) Interaction of voltagegated sodium channels with the extracellular matrix molecules tenascin-C and tenascin-R. Proc Natl Acad Sci USA 95:15753-15757.

Steward O, Zheng B, Tessier-Lavigne M (2003) False resurrections: distinguishing regenerated from spared axons in the injured central nervous system. J Comp Neurol 459:1-8.

Taylor J, Pesheva P, Schachner M (1993) Influence of janusin and tenascin on growth cone behavior in vitro. J Neurosci Res 35:347-362.

Weber P, Bartsch U, Rasband MN, Czaniera R, Lang Y, Bluethmann H, Margolis RU, Levinson SR, Shrager P, Montag D, Schachner M (1999) Mice deficient for tenascin-R display alterations of the extracellular matrix and decreased axonal conduction velocities in the CNS. J Neurosci 19:4245-4262.

Xiao ZC, Bartsch U, Margolis RK, Rougon G, Montag D, Schachner M (1997) Isolation of a tenascin-R binding protein from mouse brain membranes. A phosphacan-related chondroitin sulfate proteoglycan. J Biol Chem 272:32092-32101.

Xiao ZC, Ragsdale DS, Malhotra JD, Mattei LN, Braun PE, Schachner M, Isom LL (1999) Tenascin-R is a functional modulator of sodium channel beta subunits. J Biol Chem 274:26511-26517. 